Bull. Mater. Sci., Vol. 23, No. 4, August 2000, pp. 239-241. (C) Indian Academy of Sciences.

\title{
Phase transitions in $\mathrm{Na}_{2} \mathrm{TeO}_{4}$ ceramics
}

\author{
N K SINGH and R N P CHOUDHARY* \\ University Department of Physics, Ara 802 301, India \\ *Department of Physics and Meteorology, Indian Institute of Technology, Kharagpur 721 302, India
}

MS received 5 January 2000; revised 1 May 2000

\begin{abstract}
Polycrystalline samples of $\mathrm{NaTeO}_{4}$ were prepared by conventional solid-state reaction technique at low temperature $\left(600^{\circ} \mathrm{C}\right)$. X-ray powder diffraction (XRD) technique was used to check the formation of single phase $\mathrm{NaTeO}_{4}$ compound with cell parameters $a=10 \cdot 602(1) \AA ; b=70 \cdot 622(1) \AA$ and $c=8 \cdot 506(1) \AA$ in orthorhombic crystal system. Detailed studies of dielectric constant $(\varepsilon)$ (and loss tangent $(\tan \delta$ ) as a function of frequency $(400 \mathrm{~Hz}-10 \mathrm{kHz})$ and temperature $\left(-120^{\circ} \mathrm{C}-260^{\circ} \mathrm{C}\right)$ show that the compound has two phase transitions in the ferroelectric phase.
\end{abstract}

Keywords. Polycrystalline; phase transition; ceramics; dielectric constant.

\section{Introduction}

Since the discovery of ferroelectricity and its related properties in $\mathrm{BaTiO}_{3}$ (Wul and Goldman 1945), a large number of oxides in different forms have been studied using various experimental techniques in search of new materials for device applications such as transducers, computer memory and displays, electro-optic modulators, hydrophones, IR detectors, etc (Okada and Ossaka 1980; Deb 1988; Piligrim et al 1990; Okuyama and Hamakawa 1991; Tondon et al 1992). Tireless efforts are still going on either in search of new ferroelectrics or new compositions of known compounds. The compounds with a general formula $\mathrm{A}_{2} \mathrm{XY}_{4}(\mathrm{~A}=$ alkali metal ions or equivalent monovalent complex ions and $\mathrm{XY}_{4}=$ divalent tetravalent complex) are typical materials exhibiting commensurateincommensurate phase (Yamaguchi et al 1987) and orthorhombic $\beta-\mathrm{K}_{2} \mathrm{SO}_{4}$ type structure with space group Pmcn in their high-temperature phase. Amongst all of them, $\mathrm{K}_{2} \mathrm{ZnCl}_{4}$ is ferroelectric at room temperature and undergoes an incommensurate-commensurate phase transition at $130^{\circ} \mathrm{C}$ (Zanbergen et al 1979). The incommensurate phase of the compound transforms to the normal phase with orthorhombic structure (space group Pmcn) at $280^{\circ} \mathrm{C}$ (Gesi 1984). Further, some crystals of a general formula $\mathrm{A}_{2} \mathrm{XY}_{4}$ $(\mathrm{A}=\mathrm{Rb} ; \mathrm{X}=\mathrm{Zn}, \mathrm{Co}$ and $\mathrm{Y}=\mathrm{Cl}, \mathrm{Br})$ have similar type of successive phase transitions (Haga et al 1993; Shimizu et al 1995). From an extensive literature survey it has been found that except few works (Sharma et al 1999; Singh et al 1999), not much is known about $\mathrm{A}_{2} \mathrm{TeO}_{4}$ $(\mathrm{A}=$ alkali ions). Therefore we have carried out preliminary X-ray and detailed dielectric, polarization and electrical conductivity studies of the compounds. The present

*Author for correspondence report on $\mathrm{Na}_{2} \mathrm{TeO}_{4}$ is part of our systematic study of $\mathrm{A}_{2} \mathrm{TeO}_{4}$ family.

\section{Experimental}

The polycrystalline samples of $\mathrm{Na}_{2} \mathrm{TeO}_{4}$ were prepared by conventional high-temperature solid-state reaction technique in an air atmosphere with raw materials $\mathrm{Na}_{2} \mathrm{Co}_{3}$ (AR grade $99.9 \% \mathrm{M} / \mathrm{s}$ S.D. Fine Chem, India) and $\mathrm{TeO}_{2}$ ( $99 \% \mathrm{M} / \mathrm{s}$ Aldrich Chemical Co. Inc, USA) in a suitable stoichiometry. The compounds were thoroughly mixed in an agate-mortar for $2 \mathrm{~h}$. The mixed powders were calcined at $600^{\circ} \mathrm{C}$ for $6 \mathrm{~h}$ in alumina crucible. The process of grinding and calcination was repeated several times till the formation of the compound was confirmed. Finally calcination was completed at $600^{\circ} \mathrm{C}$. Fine homogeneous powder of the resulting materials was then used to make cylindrical pellets of diameter $10 \mathrm{~mm}$ and thickness $1-2 \mathrm{~mm}$ under an isostatic pressure of about $5.5 \times 10^{7} \mathrm{~kg} / \mathrm{m}^{2}$. Polyvinyl alcohol (PVA) was used as binder which was burnt off during the sintering of the pellets. X-ray diffraction technique was used to check the formation of $\mathrm{Na}_{2} \mathrm{TeO}_{4}$ compound prepared with reaction $\mathrm{Na}_{2} \mathrm{CO}_{3}+$ $\mathrm{TeO}_{2}+\mathrm{O}$ (obtained from air). X-ray diffractogram of the $\mathrm{Na}_{2} \mathrm{TeO}_{4}$ was recorded at room temperature using X-ray diffractometer (Philips) with $\mathrm{CoK}_{\alpha}$ radiation $(\lambda=1.789 \AA)$ in a wide range of Bragg angles $\left(10^{\circ} \leq 2 \theta \leq 65^{\circ}\right)$ at a scanning speed $2 \% \mathrm{~min}$. The sintered pellets were polished to make both their surfaces flat and parallel and were electroded with high purity silver paste for electrical measurements.

The dielectric constant $(\varepsilon)$ and loss tangent $(\tan \delta$ ) of the pellet samples were obtained as a function of frequencies $\left(400-10^{4} \mathrm{~Hz}\right)$ at room temperature, and as a function of temperature $\left(-120-260^{\circ} \mathrm{C}\right)$ at fixed frequency $(10 \mathrm{kHz})$ 
over a small temperature interval using a GR 1620 AP capacitance measuring assembly in conjunction with laboratory-made three-terminal sample holder. Measurement of dc resistivity $(\rho)$ was carried out as a function of electric field and temperature $\left(30-300^{\circ} \mathrm{C}\right)$ using a Keithley programmable electrometer.

\section{Results and discussion}

The sharp and single peak of XRD pattern of $\mathrm{Na}_{2} \mathrm{TeO}_{4}$ which was different (in position) from those of the components carbonate/oxides, suggested the formation of single-phase new compound. All the peaks of the XRD pattern were indexed and cell parameters were determined in various crystal systems with a standard computer program 'powdin'. Finally, a particular unit cell of orthorhombic system was selected for which sum of differences in observed and calculated $d$-values (i.e. $\left.\Sigma \Delta d=\Sigma\left(d_{\mathrm{obs}}-d_{\text {cal }}\right)\right)$ was found to be minimum. Table 1 shows a good agreement between observed and calculated $d$-values, which suggests the correctness of selection of crystal system and cell parameters. The finally selected cell parameters, refined by least-squares method are: $a=10 \cdot 602(1) \AA ; b=$ 10.622(1) $\AA$ and $c=8.506(1) \AA$. The linear particle size $(L)$ of the sample, calculated from X-ray diffraction profiles using Scherrer (1918) equation,

$$
L=(0 \cdot 89) \lambda /\left(\beta_{1 / 2} \cos \theta\right) \text {, }
$$

where $\beta_{1 / 2}$ is the full width at half maximum and $\theta$ gives the peak position of diffraction line, was found to be $250 \AA$.

Figure 1 shows the variation of dielectric constant $(\varepsilon)$ and loss factor $(\tan \delta)$ as a function of frequency $(400 \mathrm{~Hz}-$ $10 \mathrm{kHz}$ ). The nature of variation of these parameters shows that $\varepsilon$ and $\tan \delta$ decrease with the increase of frequency which is the normal behaviour of a dielectric. This is due to the presence of all different types of polarizations (viz. electric, dipolar, interfacial, orientational, etc)

Table 1. Comparison of $d_{\text {obs }}$ and $d_{\text {cal }}$ (in $\AA$ ) of some reflections of $\mathrm{Na}_{2} \mathrm{TeO}_{4}$ at room temperature.

\begin{tabular}{cccccc}
\hline$h$ & $k$ & $l$ & $d_{\text {obs }}$ & $d_{\text {cal }}$ & $I / I_{0}$ \\
\hline 1 & 1 & 0 & $5 \cdot 1385$ & $5 \cdot 1533$ & 100 \\
0 & 1 & 1 & $5 \cdot 0759$ & $5 \cdot 0699$ & 19 \\
2 & 0 & 3 & $4 \cdot 9317$ & $4 \cdot 9330$ & 15 \\
2 & 0 & 4 & $3 \cdot 9172$ & $3 \cdot 9139$ & 22 \\
4 & 1 & 0 & $3 \cdot 6464$ & $3 \cdot 6409$ & 18 \\
3 & 0 & 5 & $3 \cdot 4062$ & $3 \cdot 4025$ & 14 \\
2 & 0 & 5 & $3 \cdot 2207$ & $3 \cdot 2212$ & 13 \\
4 & 1 & 3 & $3 \cdot 0638$ & $3 \cdot 0638$ & 16 \\
3 & 1 & 4 & $2 \cdot 9665$ & $2 \cdot 9709$ & 25 \\
6 & 0 & 3 & $2 \cdot 8792$ & $2 \cdot 8740$ & 24 \\
7 & 0 & 0 & $2 \cdot 8563$ & $2 \cdot 8577$ & 18 \\
5 & 1 & 3 & $2 \cdot 7792$ & $2 \cdot 7820$ & 51 \\
\hline
\end{tabular}

in the compound at room temperature $\left(30^{\circ} \mathrm{C}\right)$ and low frequency. Similar dielectric behaviour was found in some ferroelectric ceramics (Bera and Choudhary 1995; Misra et al 1995).

Figure 2 shows the temperature dependence of $\varepsilon$ and $\tan \delta$ at $10 \mathrm{kHz}$ which shows two anomalies. The a.c.

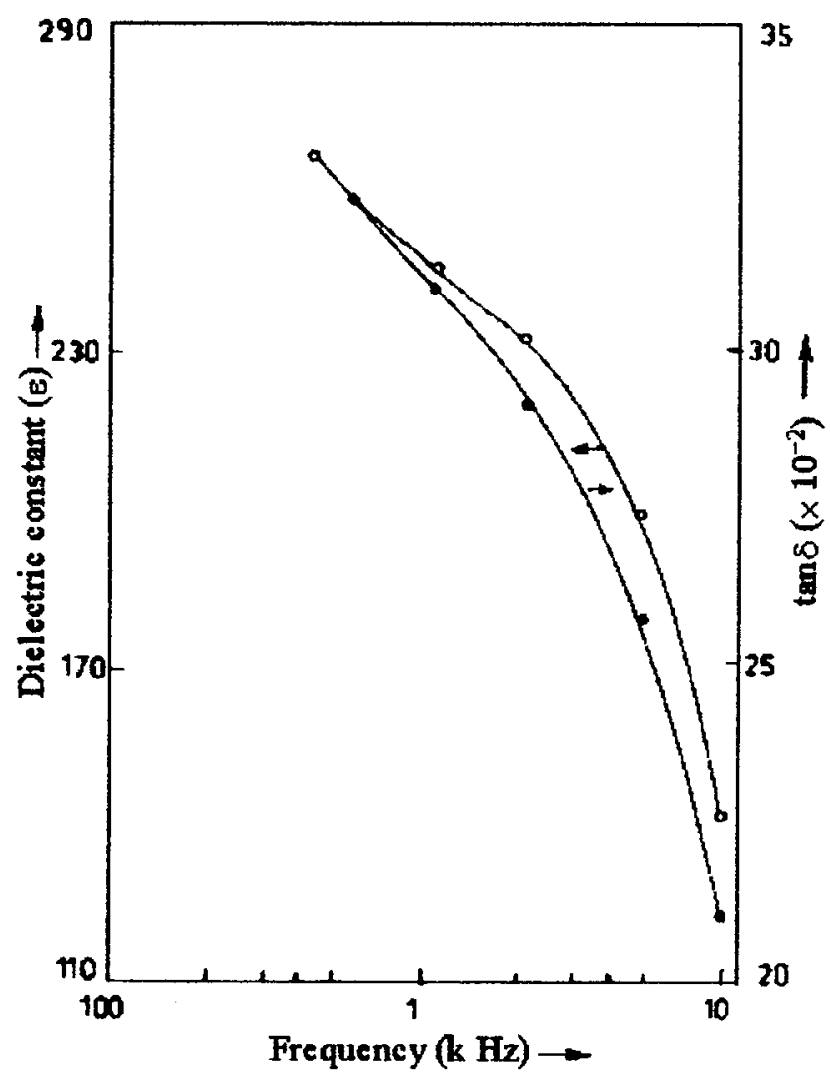

Figure 1. Variation of dielectric constant $(\varepsilon)$ and loss tangent ( $\tan \delta$ ) of $\mathrm{Na}_{2} \mathrm{TeO}_{4}$ as a function of frequency at room temperature.

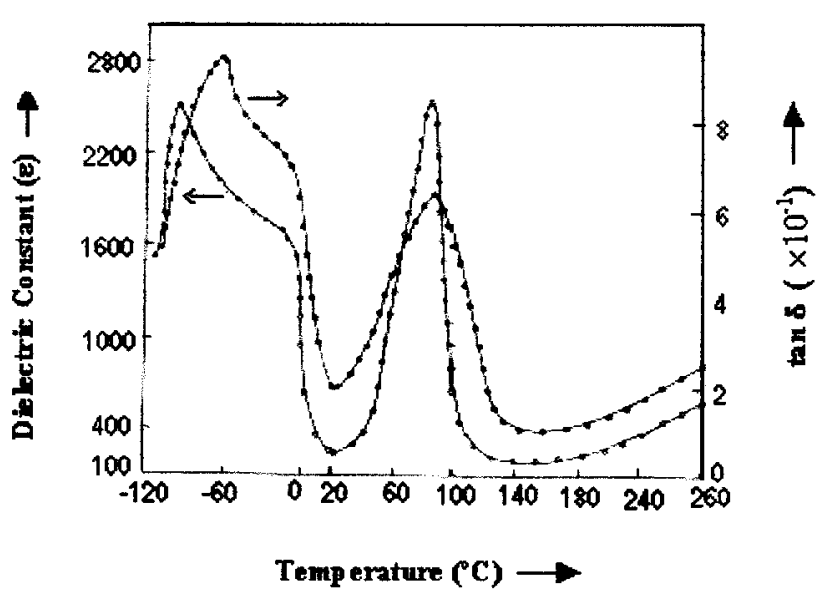

Figure 2. Variation of dielectric constant $(\varepsilon)$ and loss tangent $\left(\tan \delta\right.$ ) of $\mathrm{Na}_{2} \mathrm{TeO}_{4}$ with temperature $\left(-120^{\circ} \mathrm{C}-260^{\circ} \mathrm{C}\right)$ at $10 \mathrm{kHz}$. 


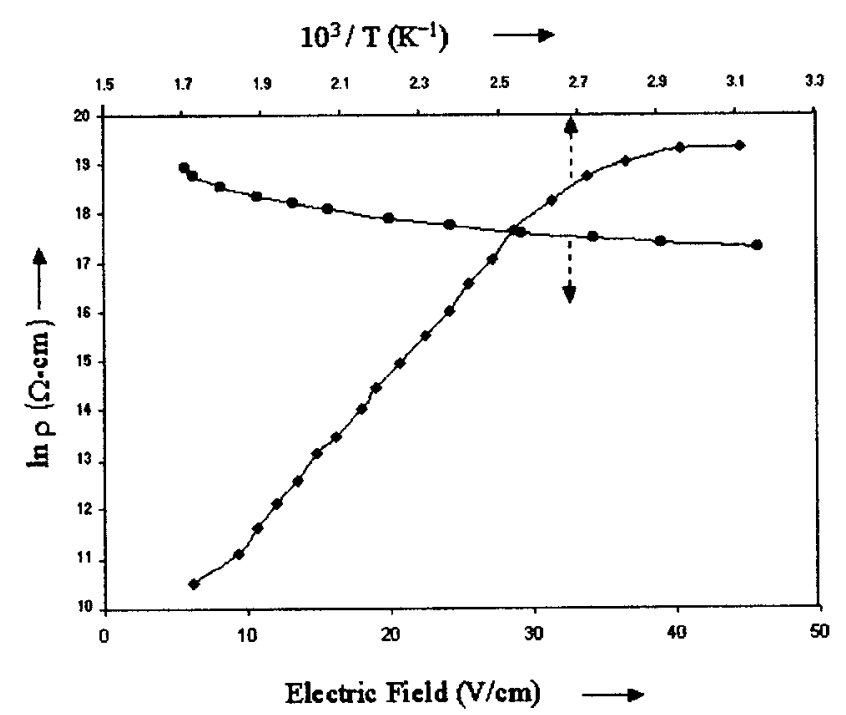

Figure 3. Variation of $\ln \rho_{\mathrm{dc}}$ as a function of inverse of absolute temperature $(1 / T)$ of $\mathrm{Na}_{2} \mathrm{TeO}_{4}$ at $10 \mathrm{kHz}$ and at constant and varying fields.

electrical conductivity $(\sigma)$ and activation energy of $\mathrm{Na}_{2} \mathrm{TeO}_{4}$ were calculated using the formula

$$
\sigma=\omega \varepsilon \varepsilon_{0} \tan \delta \text { and } \sigma=\sigma_{0} \exp \left(-E_{\mathrm{a}} / K_{\mathrm{B}} T\right),
$$

where $\omega$ is the angular frequency, $\varepsilon_{0}$ the vacuum permittivity, $E_{\mathrm{a}}$ the activation energy and $K_{\mathrm{B}}$ the Boltzmann constant. At $10 \mathrm{kHz}, E_{\mathrm{a}}$ has been calculated from the slope of the $\ln \sigma$ vs $1 / T$ graph and was found to be $0.66 \times 10^{-1} \mathrm{eV}$ in the high-temperature region. Such a low value of activation energy is due to high ionic conductivity of $\mathrm{Na}_{2} \mathrm{TeO}_{4}$ supporting the superionic nature of it in high temperature region (Anderson 1964; Robert and Newnham 1975). No proper hysteresis loop has been observed in the unpoled $\mathrm{Na}_{2} \mathrm{TeO}_{4}$ compound. The variation of d.c. resistivity as a function of electric field at room temperature is shown in figure 3 . It can be seen that the d.c. resistivity of $\mathrm{Na}_{2} \mathrm{TeO}_{4}$ decreases with increasing biasing field. Resistivity comes down with increasing biasing field.
The variation of d.c. resistivity $(\ln \rho)$ with inverse of absolute temperature $(1 / T)$, at a constant electric field $(10 \mathrm{~V} / \mathrm{cm})$ is also seen in figure 3 . It is found that resistivity decreases as temperature increases.

Finally, it is concluded that $\mathrm{Na}_{2} \mathrm{TeO}_{4}$ has an orthorhombic structure at room temperature and successive phase transitions at $-96 \pm 2{ }^{\circ} \mathrm{C}$ and $88 \pm 2{ }^{\circ} \mathrm{C}$.

\section{Acknowledgement}

We are grateful to the Central Research Facilities of IIT Kharagpur, for some experimental help.

\section{References}

Anderson J C 1964 Dielectric 1717

Bera S and Choudhary R N P 1995 J. Mater. Sci. Lett. 14568

Deb K K 1988 J. Phys. Soc. Jap. 522931

Gesi K 1984 J. Phys. Soc. Jpn. 533850

Haga H, Onodera A and Tokunago M 1993 J. Phys. Soc. Jap. 621597

Misra N K, Sati R and Choudhary R N P 1995 Mater. Lett. 24313

Okada K and Ossaka J 1980 Acta Crystallogr. B36 657

Okuyama M and Hamakawa Y 1991 Ferroelectrics 118261

Piligrim M S, Sutherland E A and Winzeer R S $1990 \mathrm{~J}$. Am. Ceram. Soc. 733122

Robert E and Newnhan R E 1975 Structure property relation (Berlin: Springer) $\mathbf{7 1}$

Scherrer P 1918 Gottin Nachricht 298

Sharma S, Choudhary R N P and Shanigrahi S R 1999 Ferroelectrics 22741

Shimizu F, Anzai T, Takashige M and Sawada S 1995 Ferroelectrics 168215

Singh N K, Sharma S and Choudhary R N P 1999 J. Electro Ceramics (in press)

Tandon R P, Singh R, Singh V, Swani N H and Hans V K 1992 J. Mater. Sci. Letts 11883

Wul B and Goldman I M 1945 C. R. Acad. Sci. USSR 46123

Yamaguchi T, Suzuki H, Shimiza H and Sawada S $1987 \mathrm{~J}$. Phys. Soc. Jap. $\mathbf{5 6} 4250$

Zanbergen H W, Verschoor G C and Ijdo D J W 1979 Acta Crystallogr. B35 1425 